\title{
Trabecular bone score and 3D-DXA in young, antiretroviral treatment-naïve patients in Madrid
}

\author{
Patricia Atencio ${ }^{1}$, Rosa Arboiro-Pinel ${ }^{2}$, Alfonso Cabello ${ }^{1}$, Francisco M. Conesa-Buendía ${ }^{3}$, \\ Miguel Górgolas ${ }^{1}$, Aránzazu Mediero ${ }^{3}$, Manuel Díaz-Curiel ${ }^{2}$
}

\author{
'Division of Infectious Diseases, IIS-Fundación Jiménez Díaz, Universidad Autónoma \\ de Madrid, Madrid, Spain \\ ${ }^{2}$ Metabolic Bone Diseases Unit, Internal Medicine Department, IIS-Fundación Jiménez \\ Díaz, Universidad Autónoma de Madrid, Madrid, Spain \\ ${ }^{3}$ Bone and Joint Research Unit, IIS-Fundación Jiménez Díaz. Universidad Autónoma de \\ Madrid, Madrid, Spain
}

Submitted: 1 February 2021

Accepted: 21 March 2021

Arch Med Sci Civil Dis 2021; 6: e52-e60

DOI: https://doi.org/10.5114/amscd.2021.105843

Copyright $\odot 2021$ Termedia \& Banach

\section{Abstract}

Introduction: Low bone mineral density (BMD) has been described as a non-AIDS-related event in human immunodeficiency virus (HIV)-patients, but it is poorly studied by dual-energy X-ray absorptiometry (DXA) and trabecular bone score (TBS) in young HIV-infected men who have received no previous antiretroviral treatment (ART).

Material and methods: A retrospective study of 56 naïve-HIV-infected men under 50 years old with recently diagnosed HIV infection, between May 2012 and July 2017.

Results: The mean age was $33.11 \pm 6.6$ years, and they were $56.4 \%$ Caucasian and $43.6 \%$ Latin American. Regarding lifestyle and risk factors, 57\% had previous exposure to tobacco and 31\% reported drug use. Low BMD (Z-score $<-2.0$ ) was found in $21.4 \%$ of the patients, and partially degraded and degraded in $25 \%$ and $1.7 \%$, respectively in TBS. We find significative prevalence of bone involvement among naïve HIV-infected men under 50 years old.

Conclusions: Further studies are necessary to evaluate if BMD assessment should be recommended in young HIV-infected patients.

Key words: trabecular bone score, 3D-DXA, human immunodeficiency virus, naïve, bone mineral density.

\section{Introduction}

Since the introduction of the first antiretroviral drugs, the life expectancy of patients infected with the human immunodeficiency virus (HIV) has increased substantially; in fact, a significant decrease in morbidity and mortality has largely closed the gap in life expectancy between HIV patients and the general population [1]. Factors such early diagnosis and initiation of antiretroviral treatment (ART) and appropriate adherence to therapy play a fundamental role in the clinical course of the disease.

Within this context, several chronic diseases now present at inordinately high rates for the age of patients in this population, one of the most prevalent being bone involvement and fracture. Low bone mineral density is notably prevalent among HIV-infected adults: it is estimated

\author{
Corresponding author: \\ Rosa Arboiro Pinel \\ Metabolic Bone \\ Diseases Unit \\ Fundación Jiménez \\ Díaz University \\ Hospital (UAM) \\ Madrid 28040, Spain \\ E-mail: RMArboiro@ \\ quironsalud.es
}


that $60 \%$ of patients present osteopaenia (op) and as many as $15 \%$ have osteoporosis (OP) [2-5].

Bone mineral density (BMD) values are a highly useful diagnostic tool for OP and risk of fracture and as a means of monitoring medical treatment. dual-energy X-ray absorptiometry (DXA), which measures the BMD of the lumbar spine, hip, and forearm, is the only method of diagnosing OP in patients who have not sustained a fragility fracture, and it is the best method of monitoring changes in BMD over time [6]. Another method, known as trabecular bone score (TBS), evaluates variations through greyscale analysis of images of the lumbar spine obtained with DXA, thereby supplying information on the microstructure of trabecular bone such as trabecular number, space, and connective density. A high TBS represents a resilient microstructure, while a low TBS indicates heterogeneous bone and a more porous trabecular network with lower bone strength [7-9]. TBS provides information on the risk of bone fracture independently of BMD [10]. The recent development of 3D-SHAPER software, which performs a 3-dimensional analysis of the femur using standard hip DXA scan, enables physicians to analyse the cortical and trabecular bone separately, thus making it possible to more fully characterize the strength of the proximal femur.

In this study, we aim to provide information on the bone characteristics of HIV-infected patients under 50 years of age who are naïve to ART, and to study the association between the bone of these individuals and previously established, traditional risk factors.

\section{Material and methods}

\section{Study design}

This retrospective study was carried out by members of the Infectious Disease Unit, Metabolic Bone Disease Unit, and Bone and Joint Research Unit of Hospital Universitario Fundación Jiménez Díaz (Madrid, Spain). Fasting blood samples and DXA images were obtained before patients began ART. The hospital research ethics committee approved the study (PIC155/2016, EO034/2014), which was conducted in compliance with the tenets of the Declaration of Helsinki.

\section{Patients}

We included male patients between the ages of 18 and 50 years, who presented to the Hospital Universitario Fundación Jiménez Díaz Infectious Disease Unit between May 2012 and July 2017 with recently diagnosed HIV infection. Patients were excluded if they had received previous ART; presented secondary causes of OP such as chronic kidney disease, thyrotoxicosis, rheumatic disease, advanced liver disease, malabsorption syndrome, cancerous growths, bone diseases, previous fragility fracture; or if they had received medication that alters bone metabolism such as systemic glucocorticoids or antiosteoporotic drugs.

Demographic data were obtained for each patient, including country of origin, age, body mass index (BMI), lifestyle habits such as tobacco, alcohol, and drug consumption, physical exercise, and comorbidities (hepatitis B and/or C infection). Low weight was defined as a BMI of under $20 \mathrm{~kg} / \mathrm{m}^{2}$. Tobacco use was determined as past or present smoking; alcohol intake at or above 30 g/day was interpreted as alcohol abuse; and drug abuse was established as consumption one or more times per week. Regular exercise was considered to be 3 or more times a week, and a healthy diet was determined as 3 servings per day of calcium-rich foods.

\section{Biochemical analysis}

The following values were obtained from patients while fasting: $25-\mathrm{OH}$ vitamin D (25OHD) (30-50 ng/ml), thyroid-stimulating hormone (TSH) (0.35-5.5 $\mu \mathrm{Ul} / \mathrm{ml})$, parathyroid hormone (PTH) (10-70 pg/ml), calcium (Ca) (8.7-10.4 mg/dl), phosphorus (P) $(2.5-4.5 \mathrm{mg} / \mathrm{dl})$, and alkaline phosphatase (AP) (45-129 UI/l). Additionally, we measured markers of bone metabolism, i.e. carboxy-terminal telopeptide of type 1 collagen (CTX) $(0.064-0.5 \mathrm{ng} / \mathrm{ml})$ and procollagen type 1 N-terminal propeptide (P1NP) (10.4-62 ng/dl). All measurements were taken using the Advia 2400 system (Siemens ${ }^{\circledast}$, Munich, Germany). Immunovirological parameters such as CD4+, CD8+ (measured by flow cytometry), and viral load of HIV-1 were measured by PCR (Roche, Basel, Switzerland).

\section{Bone mineral density}

BMD was measured using DXA images (Hologic QDR 4500C. S/N 48027. Bedford, MA, USA) taken of the lumbar spine (LS) from L2 to L4, femoral neck (FN), and total hip (TH). Results are expressed in accordance with the criteria of the WHO; because our study sample comprised patients under the age of 50 years, we used Z-score, estimating all values below -2.0 to be low BMD $[11,12]$.

\section{Trabecular bone score and DXA-based 3D modelling}

TBS was measured by applying TBS iNsight software (version 3.0; Medimaps Group, Geneva, Switzerland) when interpreting DXA images of the LS. These calculations were based on mean lumbar measurements for vertebrae L2-L4 with the following reference values: TBS $\geq 1.350$ was con- 
sidered normal, a TBS between 1.350 and 1.200 indicated partially degraded microarchitecture, and TBS $\leq 1.200$ represented degraded microarchitecture [7].

We performed 3-dimensional analyses of the proximal femur using 3D-SHAPER ${ }^{\oplus}$ software (version 2.9.0; Galgo Medical, Spain) to create specific models based on DXA studies and then separately calculated the volumetric density (VBMD) of the trabecular and cortical bone $\left(\mathrm{mg} / \mathrm{cm}^{3}\right)$. Calculations were also made for Integral VBMD (mg/ $\mathrm{cm}^{3}$ ), which measures the mean volumetric density of the trabecular and cortical compartments, providing an indicator of the overall strength of the proximal femur. Cortical surface BMD (cortical sBMD), measured in $\mathrm{mg} / \mathrm{cm}^{2}$ and calculated by multiplying the cortical thickness (Cth) in $\mathrm{cm}$ by the cortical vBMD $\left(\mathrm{mg} / \mathrm{cm}^{3}\right)$, is related to cortical bone strength: the thicker and/or denser the cortical bone, the greater the cortical surface density.

\section{Statistical analysis}

Qualitative variables are expressed as frequency and percentage values, and quantitative data appear as mean and standard deviation or median and interquartile range, depending on the degree of symmetrical distribution. All the comparisons of quantitative variables were made with the Mann-Whitney $U$, and the comparisons of qualita- tive variables with the $\chi^{2}$ or Fisher's exact test. Statistical significance was set at $p$-values $<0.05$. All analyses were carried out in R 3.6.2 (R: a language and environment for statistical computing. R Foundation for Statistical Computing. Vienna, Austria).

\section{Results}

Fifty-six male, ART-naïve patients with HIV infection were studied. Their average age was 33.1 \pm 6.6 years and they had an average BMI of 23.3 $\pm 2.4 \mathrm{~kg} / \mathrm{m}^{2} ; 64.2 \%$ were Caucasian and $33.9 \%$ were Latin American (Table I). Regarding socio-epidemiological factors, $57 \%$ reported tobacco use, $7 \%$ consumed excessive amounts of alcohol (over $30 \mathrm{~g} /$ day), and $31 \%$ abused drugs (Table I). As for comorbidities, none of the patients were positive for hepatitis B or C infection (HBVsAg+ and HCV $A b+$, respectively).

Regarding biochemical data (Table II), all patients had normal values for PTH, AP, and TSH. Median measurements for CTX and P1NP were as follows: $0.2 \mathrm{ng} / \mathrm{ml}$ and $47.1 \mathrm{ng} / \mathrm{ml}$, respectively; both parameters discretely increased in the group with low BMD $(0.3 \mathrm{ng} / \mathrm{ml}$ and $54.4 \mathrm{ng} / \mathrm{ml}$, respectively). The median 25-hydroxyvitamin D concentration in all patients was $21.5 \mathrm{ng} / \mathrm{ml}$, this parameter being lower in the group with low BMD $(14.6 \mathrm{ng} / \mathrm{ml})$, without statistical significance. This difference did not reach statistical significance. CD4 count

Table I. Demographic and anthropometric data

\begin{tabular}{|c|c|c|c|c|}
\hline Variable & Total & Normal BMD & Low BMD & $P$-value \\
\hline Age [years] & $33.1 \pm 6.6$ & $33.4 \pm 6.4$ & $31.9 \pm 7.1$ & 0.555 \\
\hline BMI $\left[\mathrm{kg} / \mathrm{m}^{2}\right]$ & $23.3 \pm 2.4$ & $23.4 \pm 2.4$ & $22.7 \pm 2.4$ & 0.536 \\
\hline \multicolumn{5}{|l|}{ Tobacco: } \\
\hline No & $14(40.0 \%)$ & $12(40.0 \%)$ & $2(40.0 \%)$ & \\
\hline Yes & $20(57.1 \%)$ & $17(56.7 \%)$ & $3(60.0 \%)$ & \\
\hline Former smoker & $1(2.9 \%)$ & $1(3.3 \%)$ & $0(0.0 \%)$ & 1.000 \\
\hline \multicolumn{5}{|l|}{ Alcohol: } \\
\hline No & 27 (93.1\%) & $19(90.5 \%)$ & $8(100 \%)$ & \\
\hline Yes & $2(6.9 \%)$ & $2(9.5 \%)$ & $0(0.0 \%)$ & 1.000 \\
\hline \multicolumn{5}{|l|}{ Drugs: } \\
\hline No & $19(65.5 \%)$ & $13(59.1 \%)$ & $6(85.7 \%)$ & \\
\hline Yes & $9(31.0 \%)$ & $8(36.4 \%)$ & $1(14.3 \%)$ & \\
\hline Former consumer & $1(3.4 \%)$ & $1(4.5 \%)$ & $0(0.0 \%)$ & 0.523 \\
\hline \multicolumn{5}{|l|}{ Exercise: } \\
\hline No & $6(40.0 \%)$ & $4(40.0 \%)$ & $2(40.0 \%)$ & \\
\hline Yes & $9(60.0 \%)$ & $6(60.0 \%)$ & $3(60.0 \%)$ & 1.000 \\
\hline \multicolumn{5}{|l|}{ Origin: } \\
\hline Latin American & $24(43.6 \%)$ & $16(37.2 \%)$ & $8(66.7 \%)$ & \\
\hline Caucasian & $31(56.4 \%)$ & $27(62.8 \%)$ & $4(33.3 \%)$ & 0.136 \\
\hline
\end{tabular}

$B M I-$ body mass index. 
Table II. Description of biochemical variables

\begin{tabular}{|lcccc|}
\hline Variable & $\begin{array}{c}\text { Total } \\
\text { Median (IR) }\end{array}$ & $\begin{array}{c}\text { Normal BMD } \\
\text { Median (IR) }\end{array}$ & $\begin{array}{c}\text { Low BMD } \\
\text { Median (IR) }\end{array}$ & $P$-value \\
\hline 25OHD $[\mathrm{ng} / \mathrm{ml}]$ & $21.5(12.49)$ & $21.9(12.94)$ & $14.6(11.47)$ & 0.153 \\
\hline TSH $[\mathrm{uUl} / \mathrm{ml}]$ & $1.6(1.130)$ & $1.6(1.250)$ & $1.9(0.853)$ & 0.597 \\
\hline PTH $[\mathrm{pg} / \mathrm{ml}]$ & $39.3(18.25)$ & $40.3(18.70)$ & $39.0(2.600)$ & 0.866 \\
\hline Ca $[\mathrm{mg} / \mathrm{dl}]$ & $9.5(0.600)$ & $9.4(0.550)$ & $9.5(0.450)$ & 0.372 \\
\hline P $[\mathrm{mg} / \mathrm{dll}]$ & $3.3(0.750)$ & $3.2(0.750)$ & $3.4(1.100)$ & 0.521 \\
\hline AP $[\mathrm{Ul} / \mathrm{l}]$ & $66.0(19.50)$ & $65.5(18.00)$ & $71.5(32.25)$ & 0.473 \\
\hline CD4 [cells/l] & $491.5(382.8)$ & $491.5(386.0)$ & $481.5(393.0)$ & 0.646 \\
\hline CD4/CD8 ratio & $0.440(0.312)$ & $0.440(0.272)$ & $0.430(0.410)$ & 0.811 \\
\hline Viral load copies/ml & $47.709(65891)$ & $52.780(73879)$ & $14.268(37609)$ & 0.104 \\
\hline CTX [ng/ml] & $0.2(0.216)$ & $0.2(0.152)$ & $0.3(0.226)$ & 0.273 \\
\hline P1NP [ng/ml] & $47.1(22.10)$ & $47.1(20.60)$ & $54.5(42.12)$ & 0.441 \\
\hline
\end{tabular}

$25 \mathrm{OHD}-25-\mathrm{OH}$ vitamin D, TSH - thyroid-stimulating hormone, PTH - parathyroid hormone (PTH), Ca - calcium, P - phosphorus, AP alkaline phosphatase, CD4-CD4 T cells, CTX - carboxy-terminal telopeptide of type 1 collagen, P1NP-procollagen type $1 \mathrm{~N}$-terminal propeptide.

showed a median concentration of 491.5 cells/l, and the CD4/CD8 ratio was 0.440 . Median viral load was 47.709 copies/ml (Table II). The other parameters were within normal range.

\section{Densitometric analysis}

A Z-score below the normal range (less than -2.0) was obtained in $21.4 \%$ of the patients studied (Table III). Table IV shows the overall results of the densitometric study and establishes a comparison between 2 subgroups based on the $Z$-score. Densitometric study revealed a mean BMD of 0.977 and $0.869 \mathrm{~g} / \mathrm{cm}^{2}$ in the $\mathrm{TH}$ and $\mathrm{FN}$, respectively. The mean BMD of the LS was 1.006 $\mathrm{g} / \mathrm{cm}^{2}$.

We found a mean TBS of $1.401 \pm 0.088$ (Table IV); $73 \%$ of the patients studied had a normal microarchitecture, $25 \%$ had partial deterioration of the microarchitecture, and $1.7 \%$ presented fully

Table III. DXA/TBS characteristics

\begin{tabular}{|lcc|}
\hline Variable & N & $\%$ \\
\hline DXA: & & \\
\hline Z-score & 44 & 78.6 \\
\hline Normal & 12 & 21.4 \\
\hline Low BMD & & \\
\hline TBS: & 38 & 73 \\
\hline Normal & 17 & 25 \\
\hline Partially degraded & 1 & 1.7 \\
\hline Degraded & & \\
\hline
\end{tabular}

DXA - dual-energy X-ray absorptiometry, TBS - trabecular bone score. deteriorated microarchitecture (Table III). Regarding the TBS images displayed in Figures $1 \mathrm{~A}, \mathrm{~B}$, panel A shows a normal TBS (1.604), while panel B shows the most severe deterioration observed in our sample (1.166).

As for the 3D analytical parameters used to determine femoral density, the following mean values were obtained: trabecular vBMD: 221.7 $\pm 36.48 \mathrm{mg} / \mathrm{cm}^{3}$; cortical vBMD: $797.4 \pm 50.98$ $\mathrm{mg} / \mathrm{cm}^{3}$; integral vBMD: $345.4 \pm 47.75 \mathrm{mg} / \mathrm{cm}^{3}$; Cth: $2.076 \pm 0.199 \mathrm{~mm}$; and cortical sBMD: 165.9 $\pm 22.14 \mathrm{mg} / \mathrm{cm}^{2}$ (Table IV). Figures $1 \mathrm{C}$, D contains the 3D-DXA image corresponding to the highest and lowest cortical SBMD readings, respectively.

Greater bone involvement can be concluded in all imaging tests of the Low BMD group, having statistical significance with respect to the group with normal BMD.

\section{Comparison of densitometric results}

An analysis of the association between TH BMD and each of the 3D-DXA parameters revealed a strong correlation $(95 \% \mathrm{Cl}, p<0.001)$ with cortical sBMD (0.95), trabecular vBMD (0.89), integral vBMD 0.89), and Cth (0.87) (Figure 2). When we compared BMD of the femoral neck, we found this value to be correlated with cortical SBMD (0.80) and trabecular vBMD (0.80) (Figure 3).

\section{Discussion}

The results of this study show that males under 50 years of age, HIV-infected, with no previous ART present bone involvement. Furthermore, the patients studied here presented risk factors for 
Table IV. Densitometric data

\begin{tabular}{|lcccc|}
\hline Variable & $\begin{array}{c}\text { Total } \\
\text { Mean } \pm \text { SD }\end{array}$ & $\begin{array}{c}\text { Normal BMD } \\
\text { Mean } \pm \text { SD }\end{array}$ & $\begin{array}{c}\text { Low BMD } \\
\text { Mean } \pm \text { SD }\end{array}$ & $P$-value \\
\hline LS BMD & $1.006 \pm 0.120$ & $1.045 \pm 0.105$ & $0.868 \pm 0.047$ & $<0.001$ \\
\hline TH BMD $\left[\mathrm{g} / \mathrm{cm}^{2}\right]$ & $0.977 \pm 0.115$ & $1.004 \pm 0.113$ & $0.879 \pm 0.054$ & $<0.001$ \\
\hline FN BMD $\left[\mathrm{g} / \mathrm{cm}^{2}\right]$ & $0.869 \pm 0.113$ & $0.884 \pm 0.119$ & $0.816 \pm 0.069$ & 0.051 \\
\hline TBS & $1.401 \pm 0.088$ & $1.426 \pm 0.076$ & $1.312 \pm 0.071$ & $<0.001$ \\
\hline Cortical sBMD $\left[\mathrm{mg} / \mathrm{cm}^{2}\right]$ & $165.9 \pm 22.14$ & $170.6 \pm 21.59$ & $148.8 \pm 14.83$ & 0.003 \\
\hline Trabecular vBMD $\left[\mathrm{mg} / \mathrm{cm}^{3}\right]$ & $221.7 \pm 36.48$ & $227.1 \pm 38.22$ & $201.9 \pm 19.97$ & 0.034 \\
\hline Integral vBMD $\left[\mathrm{mg} / \mathrm{cm}^{3}\right]$ & $345.4 \pm 47.75$ & $353.0 \pm 48.93$ & $317.4 \pm 30.90$ & 0.029 \\
\hline Cortical vBMD $\left[\mathrm{mg} / \mathrm{cm}^{3}\right]$ & $797.4 \pm 50.98$ & $808.9 \pm 46.48$ & $755.2 \pm 45.56$ & 0.002 \\
\hline Cth $[\mathrm{mm}]$ & $2.076 \pm 0.198$ & $2.105 \pm 0.199$ & $1.970 \pm 0.162$ & 0.036 \\
\hline
\end{tabular}

LS BMD - lumbar spine bone mineral density, $T H B M D$ - total hip bone mineral density, FN BMD - femoral neck bone mineral density, TBS - trabecular bone score, Cortical SBMD - cortical surface bone mineral density, Trabecular VBMD - trabecular volumetric bone mineral density, Integral VBMD - integral volumetric bone mineral density, Cortical vBMD - cortical volumetric bone mineral density, Cth - cortical thickness.
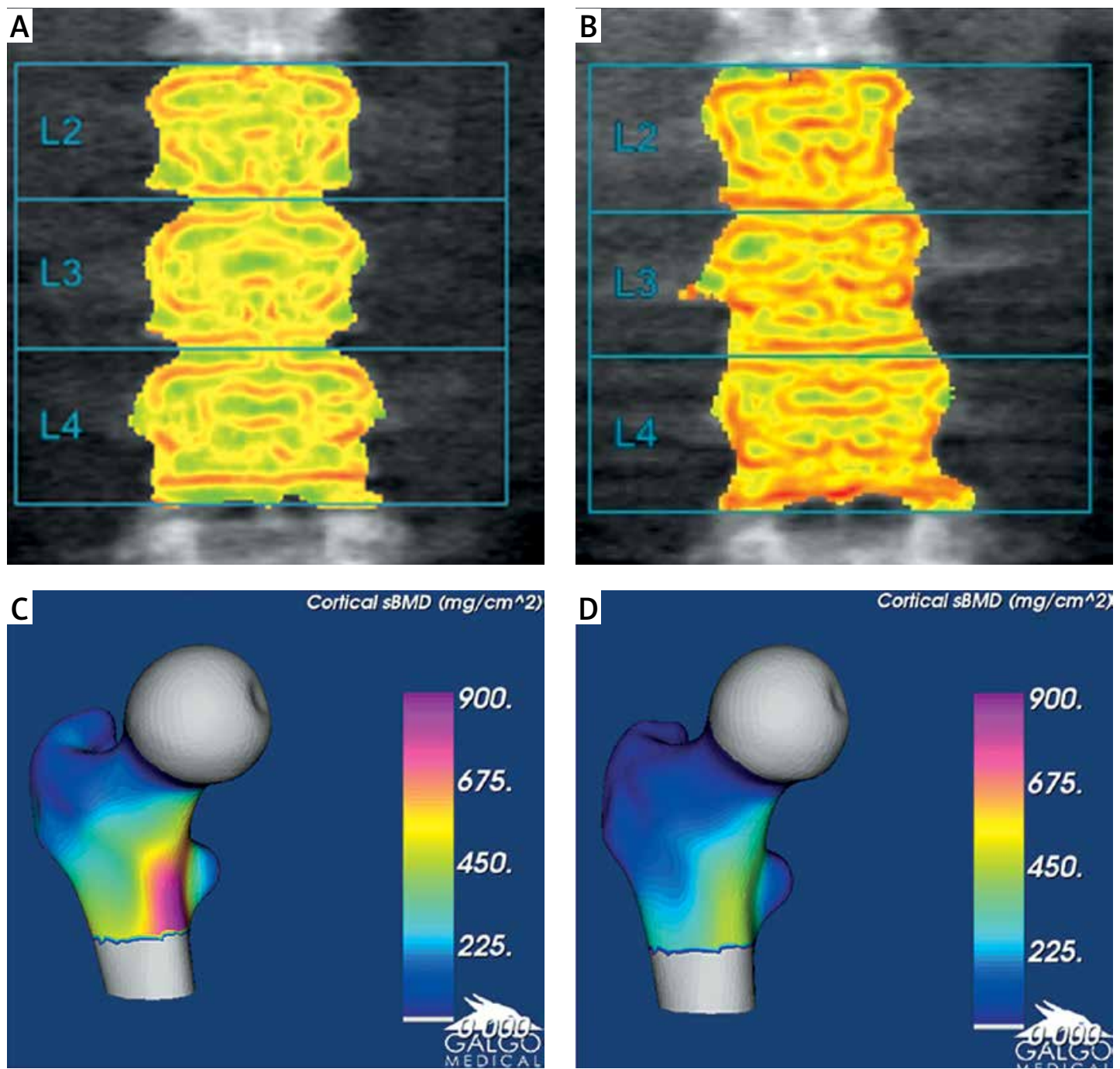

Figure 1. Differences among normal and affected TBS and 3D-DXA. A - TBS with normal microarchitecture (1.604). B - TBS corresponding to a patient with degraded microarchitecture (1.159). C - 3D-DXA Image corresponding to the highest and lowest. D - cortical SBMD in the series 

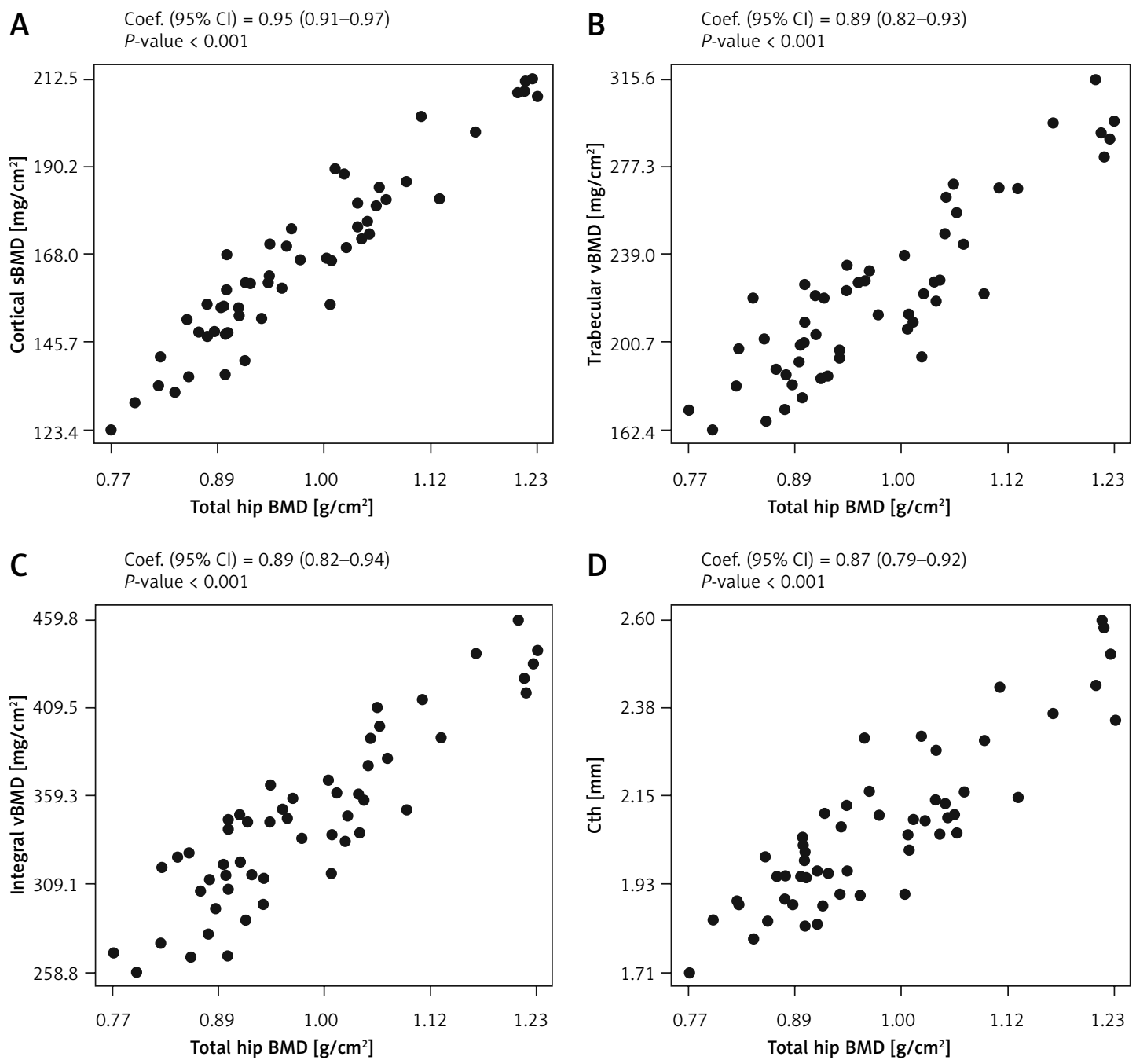

Figure 2. Correlations between total BMD and 3D parameters. A - Correlations between cortical SBMD and total hip BMD. B - Correlations between trabecular vBMD and total hip BMD. C - Correlations between integral vBMD and total hip BMD. D - Correlations between Cth and total hip BMD.
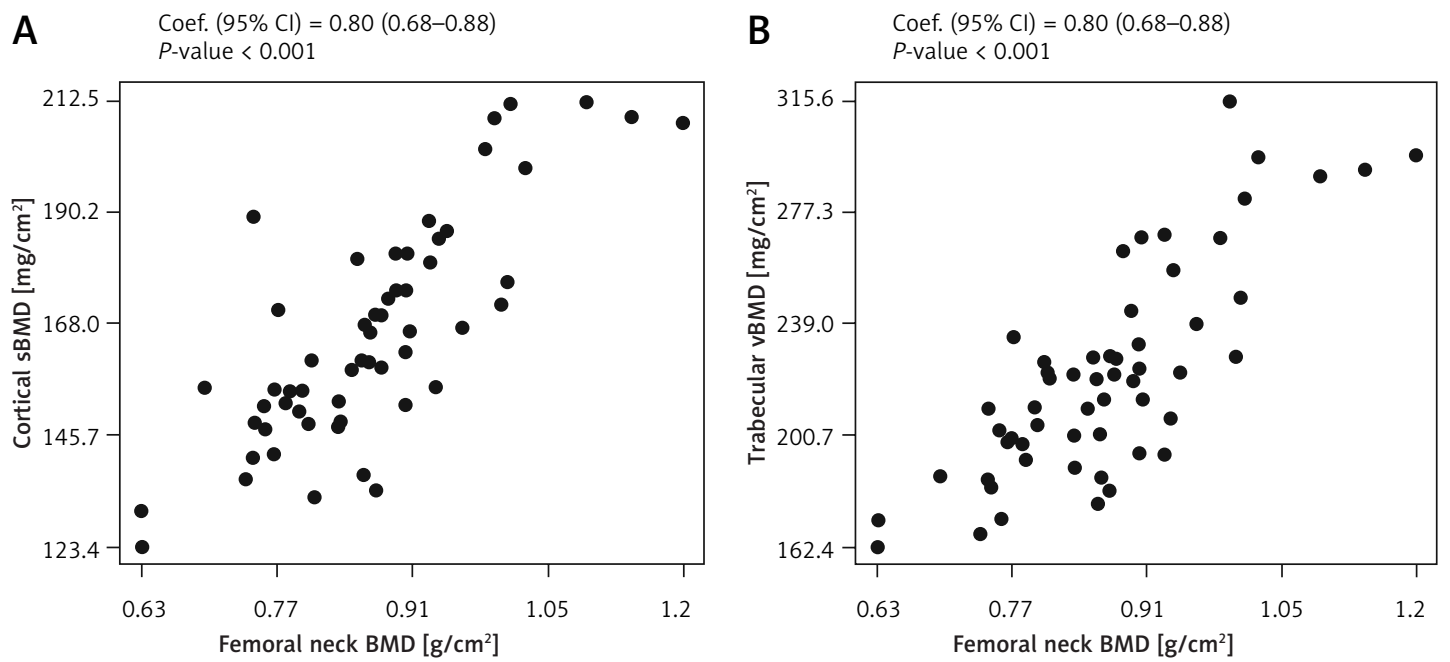

Figure 3. Correlations between femoral neck BMD and 3D parameters. A-Correlations between cortical sBMD and femoral neck BMD. B - Correlations between trabecular VBMD and femoral neck BMD 


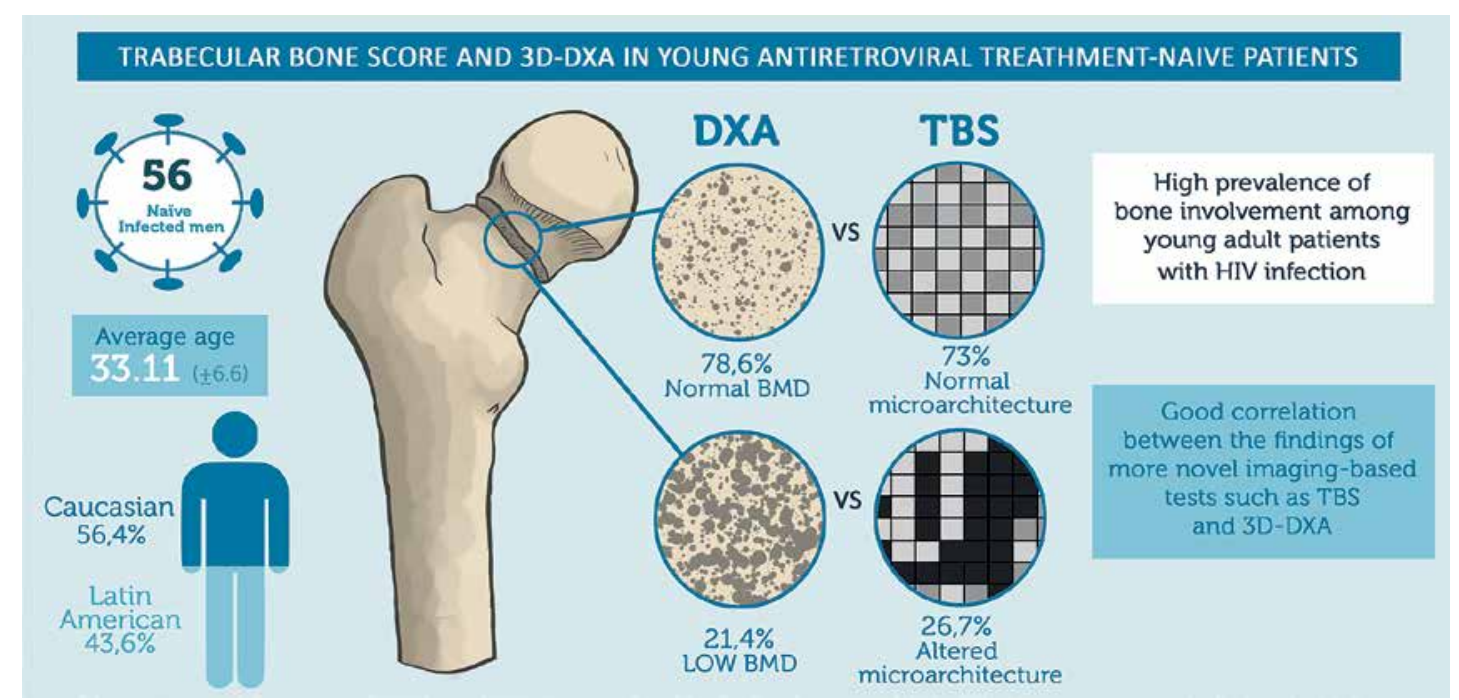

Figure 4. Trabecular Bone Score and 3D-DXA in young antiretroviral treatment-naïve patients. Summary of data.

bone involvement such as alcohol and drug use and a sedentary lifestyle as well as insufficiently high levels of vitamin D (Figure 4).

Several studies have reported that patients living with HIV infection have a higher risk of fracture than the general population [4, 13-16]. Though BMD is a key tool for assessing bone health, in certain clinical situations such as HIV infection, deterioration of bone quality is a more relevant factor than bone density [14]. Application of noninvasive, qualitative means to evaluate bone microarchitecture such as TBS and 3D modelling may be of use in assessing the risk of fracture in this population. Most available data on BMD in subjects with HIV infection have used $T$-score criteria to assess osteoporosis and osteopaenia, revealing a prevalence of $15 \%$ and $52 \%$, respectively $[17,18]$. In our research, as the mean age of the subjects studied was $33.1 \pm 6.6$ years, the $Z$-score was considered the most appropriate statistical method of determining BMD in this population, thus reflecting the criteria of the ISCD [12]; through these means, $21.4 \%$ of the patients were found to have a low $\mathrm{BMD}$, which is similar to the rate found by Paccou et al. [19] and higher than that reported by other studies in young patients $[18,20]$.

Regarding TBS of the lumbar spine, $25 \%$ of the patients in our sample presented partially deteriorated bone microarchitecture, $1.7 \%$ showed full deterioration, and the rest (73\%) had a normal microarchitecture (Table III). A literature search yielded few studies like ours performed in young treatment-naïve HIV patients, one exception being that of Güerri-Fernández et al., who studied 40 patients with a mean age of 38 years, 18 of whom (45\%) were found to have a low BMD on DXA imaging and a mean TBS of 1.357 [21].

We believe that the use of TBS is relevant when evaluating these patients, because it is a measure that is related to bone quality and correlates more closely with risk of fracture than BMD, which is a more useful indicator of bone-mass quantity. In a study by Ciullini et al. [18] using patients with a mean age of 43 years undergoing stable ART, $12.8 \%$ of whom had a lower BMD compared to the average for their age, the authors found no significant difference in the association between fractures of the vertebra and BMD, although patients with low TBS showed a greater prevalence of fracture, and this difference reached statistical significance $(p=0.003)$.

Yin et al. [22] studied patients between 20 and 25 years of age, who were receiving stable ART regimens, comparing these to individuals not infected with HIV; the authors reported a significant decrease in total $V B M D$ at the radius and tibia, mostly owing to a deficit in the trabecular compartment. Although no differences were found in cortical VBMD, patients with HIV infection had a significantly lower cortical thickness and markedly abnormal trabecular microarchitecture in both the radius and tibia.

There are no reference data that can be used when evaluating the features of cortical and trabecular bone from 3D-DXA images. In 2016 a paper was presented before the conference of the Spanish Society for Bone and Mineral Research, which examined 571 healthy women between the ages of 20 and 100 years; the authors describe a peak in trabecular VBMD of $0.158 \pm 0.04$ $\mathrm{g} / \mathrm{cm}^{3}$ at age 35 years, a peak cortical $v B M D$ of $1.052 \pm 0.018 \mathrm{~g} / \mathrm{cm}^{3}$ at age 45 years, and a peak Cth at age 45 years of $1.90 \pm 0.20 \mathrm{~mm}$. These were proposed as reference values for use in clinical settings [23]. If these values are applied to our sample of males for guidance, we see that the patients we studied had a higher mean trabecular vBMD, similar Cth values, and a lower mean 
cortical vBMD. We reach similar conclusions if we use as reference values the 3D-DXA images from the group of 104 healthy controls (16 male patients, mean age: $54.1 \pm 12$ ) included in a study on HIV-negative patients. Comparing our population to the control group in the aforementioned study, our patients had lower mean cortical VBMD (870.85 $\left.(90.8) \mathrm{mg} / \mathrm{cm}^{3}\right)$ and similar cortical sBMD (171.58 (23.9) $\left.\mathrm{mg} / \mathrm{cm}^{2}\right)$ [24]. A control group in a Spanish study [25] comprising 76 healthy individuals with characteristics that more closely resemble those of our population (i.e. $50 \%$ male, mean age of $33 \pm 10$ years, mean BMI $24 \pm 3.4 \mathrm{~kg} /$ $\mathrm{m}^{2}$ ) than the previously mentioned studies presented mean values for cortical sBMD (164 \pm 22 $\left.\mathrm{mg} / \mathrm{cm}^{2}\right)$, trabecular $\operatorname{VBMD}\left(216 \pm 40 \mathrm{mg} / \mathrm{cm}^{3}\right)$, cortical $\left(809 \pm 43 \mathrm{mg} / \mathrm{cm}^{3}\right)$ and integral vBMD $\left(345 \pm 51 \mathrm{mg} / \mathrm{cm}^{3}\right)$, and Cth $(2.02 \pm 0.2 \mathrm{~mm})$ that are consistent with those of our population.

In our study, the median vitamin D was 21.54 $\mathrm{ng} / \mathrm{ml}$, which was lower in the group with low BMD $(14.61 \mathrm{ng} / \mathrm{ml})$. A study by Ceballos et al. [26], which evaluated vitamin D levels in 70 treatment-naive HIV patients with a mean age of 31 years (range: 19-50) and included a control group comprising 21 healthy volunteers, found deficient levels of vitamin D in $66 \%$ of patients and $48 \%$ of controls; a comparison of mean $250 \mathrm{HD}$ between patients and controls showed significantly low levels among those with HIV infection $(p=0.04)$.

Our study has a number of limitations, including its retrospective, single-centre design and the small sample size used. Future prospective studies would further contribute to the knowledge of bone health at early ages in HIV.

In conclusion, our study confirms significative prevalence of bone involvement among adult patients under 50 years, with HIV infection and the correlation between the findings of more novel imaging-based tests such as TBS and 3D-DXA. In light of these results, we believe it would be beneficial to provide HIV patients with calcium and vitamin D supplements where required, because doing so would help limit the influence of prevalent risk factors in this population.

\section{Acknowledgments}

Patricia Atencio and Rosa Arboiro-Pinel contributed equally to this study. Aránzazu Mediero and Manuel Díaz-Curiel contributed equally to this study.

We would like to acknowledge Oliver Shaw for translating the manuscript, Ignacio Mahillo for statistical analysis, and Juan Sanchez-Verde Bilbao and Guido Rodríguez de Lema-Tapetado for the visual abstract.

This work has been funded with research grants from the 'Instituto de Salud Carlos III'
(PI16/00991 and PI19/00744). AM was supported by "Instituto de Salud Carlos III" through the "Miguel Servet" Program (CP15/00053), co-funded by "Fondo Europeo de Desarrollo Regional (FEDER)". No other competing interests exist.

\section{Conflict of interest}

$A C$ has received honoraria and speakers' fees from Gilead Sciences, MSD and ViiV. MG has received speakers' fees from ViiV. AM has filed a patent on use of adenosine A2AR agonists to prevent prosthesis loosening (pending) and a separate patent on use of A2AR agonists and agents that increase adenosine levels to promote bone formation/regeneration. No other conflict of interest exist.

\section{References}

1. Brooks JT, Buchacz K, Gebo KA, Mermin J. HIV infection and older Americans: the public health perspective. Am J Public Health 2012; 102: 1516-26.

2. Arnsten JH, Freeman R, Howard AA, Floris-Moore M, Lo Y, Klein RS. Decreased bone mineral density and increased fracture risk in aging men with or at risk for HIV infection. AIDS 2007; 21: 617-23.

3. Haskelberg H, Carr A, Emery S. Bone turnover markers in HIV disease. AIDS Rev 2011; 13: 240-50.

4. Triant VA, Brown TT, Lee H, Grinspoon SK. Fracture prevalence among human immunodeficiency virus (HIV)-infected versus non-HIV-infected patients in a large U.S. healthcare system. J Clin Endocrinol Metab 2008; 93: 3499-504.

5. Sharma A, Flom PL, Weedon J, Klein RS. Prospective study of bone mineral density. AIDS 2011; 24: 2337-45.

6. Marshall D, Johnell O, Wedel H. Meta-analysis of how well measures of bone mineral density predict occurrence of osteoporotic fractures. BMJ 1996; 312: 1254-9.

7. Silva BC, Boutroy S, Zhang C, et al. Trabecular bone score (TBS): a novel method to evaluate bone microarchitectural texture in patients with primary hyperparathyroidism. J Clin Endocrinol Metab 2013; 98: 1963-70.

8. Silverberg SJ, Clarke BL, Peacock M, et al. Current issues in the presentation of asymptomatic primary hyperparathyroidism: proceedings of the Fourth International Workshop. J Clin Endocrinol Metab 2014; 99: 3580-94.

9. Silva BC, Leslie WD, Resch $\mathrm{H}$, et al. Trabecular bone score: a noninvasive analytical method based upon the DXA image. J Bone Miner Res 2014; 29: 518-30.

10. McCloskey EV, Odén A, Harvey NC, et al. A meta-analysis of trabecular bone score in fracture risk prediction and its relationship to FRAX. J Bone Miner Res 2016; 31: 940-8.

11. World Health Organization. Assesment of fracture risk and its application to screening for postmenopausal osteoporosis. WHO. Technical report series. Ginebra. Suiza 1994.

12. 2019 ISCD Official Positions - Adult - International Society for Clinical Densitometry (ISCD). Available at: http://www.iscd.org/official-positions/2019-iscd-official-positions-adult/[Accessed October 28, 2019].

13. Young B, Dao CN, Buchacz K, Baker R, Brooks JT. Increased rates of bone fracture among HIV-infected persons in the HIV outpatient study (HOPS) compared with 
the US general population, 2000-2006. Clin Infect Dis 2011; 52: 1061-8.

14. Güerri-Fernández R, Molina D, Villar-García J, et al. Brief Report: HIV Infection Is Associated with Worse Bone Material Properties, Independently of Bone Mineral Density. J Acquir Immune Defic Syndr 2016; 72:314-8.

15. Güerri-Fernandez R, Vestergaard P, Carbonell C, et al. HIV infection is strongly associated with hip fracture risk, independently of age, gender, and comorbidities: a population-based cohort study. J Bone Miner Res 2013; 28: 1259-63.

16. Prieto-Alhambra D, Güerri-Fernández R, De Vries F, et al. HIV infection and its association with an excess risk of clinical fractures. JAIDS J Acquir Immune Defic Syndr 2014; 66: 90-5.

17. Brown TT, Qaqish RB. Antiretroviral therapy and the prevalence of osteopenia and osteoporosis: a meta-analytic review. AIDS 2006; 20: 2165-74.

18. Ciullini L, Pennica A, Argento G, et al. Trabecular bone score (TBS) is associated with sub-clinical vertebral fractures in HIV-infected patients. J Bone Miner Metab 2018; 36: 111-8.

19. Paccou J, Viget N, Drumez E, Cortet B, Robineau O. Prevalence and risk factors for low bone mineral density in antiretroviral therapy-naive HIV-infected young men. Médecine Mal Infect 2018; 48: 442-8.

20. Dave JA, Cohen K, Micklesfield LK, Maartens G, Levitt NS Antiretroviral therapy, especially efavirenz, is associated with low bone mineral density in HIV-infected South Africans. PLoS One 2015; 10: e0144286.

21. Güerri-Fernández R, Lerma-Chippirraz E, Fernandez Marron $\mathrm{A}$, et al. Bone density, microarchitecture, and tissue quality after 1 year of treatment with tenofovir disoproxil fumarate. AIDS Lond Engl 2018; 32: 913-20.

22. Yin MT, Lund E, Shah J, et al. Lower peak bone mass and abnormal trabecular and cortical microarchitecture in young men infected with HIV early in life. AIDS 2014; 28: 345-53.

23. Fonollà R, Nogues X, Malouf J, Romera J HL. Datos de referencia para medidas del hueso cortical y trabecular mediante la tecnología 3D-DXA. SEIOMM 2016; 8: 29.

24. Kužma M, Vaňuga P, Ságova I, et al. Non-invasive DXAderived bone structure assessment of acromegaly patients: a cross-sectional study. Eur J Endocrinol 2019; 180: 201-11.

25. García Hoyos M, Humbert L, Salmón Z, Riancho JA, Valero C. Analysis of volumetric BMD in people with Down syndrome using DXA-based 3D modeling. Arch Osteoporos 2019; 14: 98.

26. Ceballos ME, Carvajal C, Jaramillo J, Dominguez A, González G. Vitamin D and bone mineral density in HIV newly diagnosed therapy-naive patients without any secondary causes of osteoporosis. Calcif Tissue Int 2019; 104: 42-9. 